\title{
What have we learnt from measles outbreaks in 3 English cities? A qualitative exploration of factors influencing vaccination uptake in Romanian and Roma Romanian communities
}

\author{
Sadie Bell ${ }^{1 *}$ (D), Vanessa Saliba ${ }^{2}$, Mary Ramsay ${ }^{2}$ and Sandra Mounier-Jack ${ }^{1}$
}

\begin{abstract}
Background: Since 2016, large scale measles outbreaks have heavily affected countries across Europe. In England, laboratory confirmed measles cases increased almost four-fold between 2017 and 2018, from 259 to 966 cases. Several of the 2017-18 measles outbreaks in England particularly affected Romanian and Roma Romanian communities, with the first outbreaks in these communities occurring in Birmingham, Leeds and Liverpool. This study explored factors influencing vaccination behaviours amongst Romanian and Roma Romanian communities in these three cities.

Methods: Across Birmingham, Leeds and Liverpool, we conducted semi-structured interviews with 33 key providers to explore their experience in delivering vaccinations and managing the outbreak response. We also interviewed 9 Romanian women in one of the cities to explore their vaccination attitudes and behaviours. To categorise factors affecting vaccination we applied the 5As Taxonomy for Determinants of Vaccine Uptake (Access, Affordability, Awareness, Acceptance and Activation) during data analysis.

Results: Factors related to access and acceptance, such as language and literacy, ease of registering with a general practice, and trust in health services, were reported as the main barriers to vaccination amongst the communities. Concerns around vaccination safety and importance were reported but these appeared to be less dominant contributing factors to vaccination uptake. The active decline of vaccinations amongst interviewed community members was linked to distrust in healthcare services, which were partly rooted in negative experiences of healthcare in Romania and the UK.

\footnotetext{
* Correspondence: sadie.bell@lshtm.ac.uk

'Department of Global Health and Development, Faculty of Public Health and Policy, London School of Hygiene \& Tropical Medicine, 15-17 Tavistock Place, London WC1H 9SH, UK

Full list of author information is available at the end of the article
}

(c) The Author(s). 2020 Open Access This article is licensed under a Creative Commons Attribution 4.0 International License, which permits use, sharing, adaptation, distribution and reproduction in any medium or format, as long as you give appropriate credit to the original author(s) and the source, provide a link to the Creative Commons licence, and indicate if changes were made. The images or other third party material in this article are included in the article's Creative Commons licence, unless indicated otherwise in a credit line to the material. If material is not included in the article's Creative Commons licence and your intended use is not permitted by statutory regulation or exceeds the permitted use, you will need to obtain permission directly from the copyright holder. To view a copy of this licence, visit http://creativecommons.org/licenses/by/4.0/ The Creative Commons Public Domain Dedication waiver (http://creativecommons.org/publicdomain/zero/1.0/) applies to the data made available in this article, unless otherwise stated in a credit line to the data. 


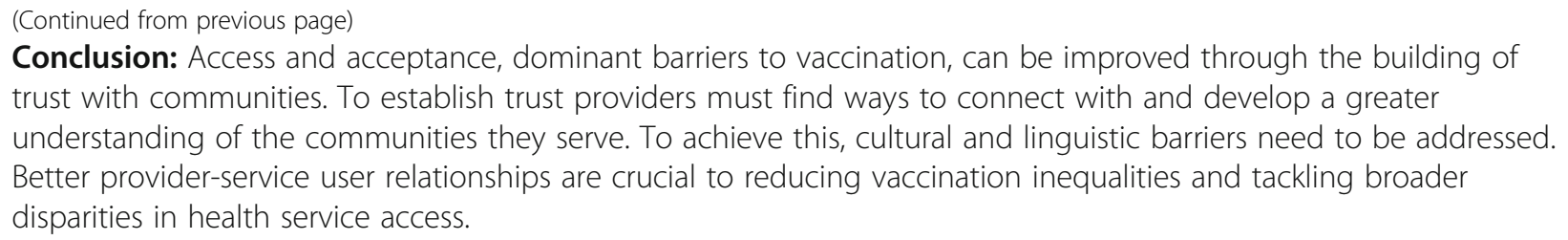

Keywords: Vaccination, Measles, Romanian communities, Roma communities, England, Inequalities, Vaccination attitudes and behaviours, Vaccination access, Primary health care

\section{Background}

Measles is a highly contagious viral disease, associated with substantial levels of morbidity and mortality [1]. A goal within the European Vaccine Action Plan is to eliminate measles from the European Region by 2020 [2]. However, since 2016, following over a decade in which Europe experienced a decline in measles cases, large scale measles outbreaks have occurred across the region [3].

In 2018, there were 83,540 measles cases and 74 measles-related deaths in the World Health Organisation (WHO) European Region, compared to 5273 measles cases and 13 measles related deaths in 2016 [4]. England has also been hit by a sharp and persistent increase in measles cases, despite the two-dose MMR vaccination that protects against measles, mumps and rubella being provided freely on the National Health Service (NHS) through general practice (GP). Between 1st January 2018 and 31st December 2018, there were 966 laboratory confirmed measles cases in England, more than tripling from 259 during the whole of 2017 [5].

The European Centre for Disease Prevention and Control highlights that populations on the move within Europe are at risk of under-vaccination and therefore more susceptible to vaccine-preventable diseases. Factors that affect vaccination access amongst migrant populations include difficulties understanding and navigating different health systems, and overcoming cultural and linguistic barriers [6,7].

Recent outbreaks in England have been linked to the travel of under-vaccinated people to measles endemic countries in Europe, and the subsequent transmission of measles in England to communities with poor vaccination coverage. These include people that may have missed vaccinations during the 'Wakefield' MMR scare, and other populations known to have lower vaccination coverage such as Traveller, migrant, the ultra-Orthodox Jewish, and Anthroposophic (Steiner) communities [8].

Several of the 2017-18 measles outbreaks in England specifically affected Romanian and Roma Romanian communities [8]. In 2017, there were just under 400,000 Romanian born residents living in the UK [9]. Although the number of Roma and their nationality is not accurately known, estimates indicate the total number of Roma in the UK to be at least 200,000 [10].
Although Gypsies, Roma and Travellers (GRT) are often considered collectively, due to similarities in their customs, beliefs, and experiences of marginalisation, each are a distinct ethnic group [11]. The UK's Roma are mainly sedentary communities living in fixed accommodation. Roma in the UK are from Eastern and Central Europe, with origins in West India. Roma have a distinct language, Romani or Romanes, which contains many different dialects, and may speak the language of their nationality (e.g. Romanian, Czech, Slovak) as a second language.

Roma are one of the largest and most marginalised ethnic minority groups in Europe and have experienced an extensive history of discrimination, persecution, and social exclusion $[12,13]$. In the UK, Roma experience inequalities in standards of living, education, employment, and health [14-18]. Romanian communities in the UK have also been found to experience health inequalities [19], and encounter discrimination [20].

As health datasets do not routinely record information by nationality or minority ethnic group, vaccination uptake amongst Romanian and Roma Romanian communities in the UK is not known. However, numerous studies across Europe have found vaccination uptake to be lower amongst Roma compared to non-Roma communities across Europe [21-23]. Vaccination uptake has also been reported as lower in Romania compared to other European countries but has not been examined amongst Romanian communities in the UK. In the UK, coverage of MMR first-dose at 12 months in 2018 was $92 \%$ and for MMR second-dose at 3 years and 4 months was $88 \%$. In Romania, coverage of MMR first-dose at 12 months in 2018 was $90 \%$ and for MMR second-dose at 5 years was $81 \%$, and there were around 1300 measles cases reported in Romania between March 2018 and February 2019 [24].

As Romanian and Roma communities are at risk of under-vaccination and were affected by measles outbreaks in 2017-18 in England, we conducted a qualitative interview study to explore factors contributing to vaccination uptake amongst these communities. Understanding these factors is crucially needed to effectively address inequalities in vaccination uptake and meet the health needs of these communities. 


\section{Methods}

Our study took place in Birmingham, Leeds and Liverpool (Table 1), cities that experienced measles outbreaks in 2017-18 that particularly affected Romanian and Roma Romanian communities.

We conducted semi-structured interviews with providers involved in vaccination delivery and outbreak management in each city, including frontline vaccinators and representatives from Public Health England (PHE) Health Protection Teams, Screening and Immunisation Teams and Local Authorities. We identified and approached providers through PHE Health Protection Teams in each city. The teams were able to link us with providers that they considered key in the outbreak response.

Written informed consent was obtained from all study participants. The interviews lasted 30-45 min and took place in person or via telephone. Providers were asked about their experiences in delivering vaccination services to Romanian and Roma service users.

To gain insight from the communities, we also conducted semi-structured interviews with Romanian community members (CMs) living in one of the cities. This deviated from our original proposal to interview CMs in each of the cities, due to difficulties in identifying and engaging with CMs within the timeframe of the study. CM recruitment took place through an Eastern European women's community group led by a Gypsy, Roma and Traveller Outreach worker. Eligible CM participants included parents and grandparents. Interviews with $\mathrm{CMs}$ lasted approximately $30 \mathrm{~min}$ and were conducted faceto-face, with the assistance of a Romanian speaking female interpreter. During the interviews, we asked the CMs to talk about their vaccination experiences in relation to themselves and any children/grandchildren. CMs were compensated with a $£ 10$ gift voucher.

Interviews were transcribed verbatim and analysed thematically using the stages outlined by Braun and Clarke [25]. During theme generation, a matrix was created using the "5A's Taxonomy for Determinants of Vaccine Uptake" to categorise factors associated with vaccine uptake [26]. The categories within the taxonomy are: Access, Affordability, Awareness, Acceptance and Activation [26] (Table 2). Contributing factors to vaccine uptake were classified in this way to identify where to target recommendations to improve uptake.

\section{Results}

Participants

Interviews were conducted with 33 providers and 9 CMs. The CMs were all women, and 3 of these women self-identified as Roma. Providers from a range of job roles were recruited from different organisations on the basis that they were involved in vaccination delivery to Romanian and Roma Romanian communities, or in an outbreak response. Participant demographic characteristics are reported in Tables 3 and 4.

Ten main factors were reported to influence vaccination uptake: primary care accessibility and acceptability, language and literacy, perceptions around vaccination costs, competing priorities to vaccination, awareness of vaccines and access to vaccine information, perceptions around measles severity and the benefits of vaccination, trust in the healthcare system and vaccines, and prompts to vaccinate. These factors are explored under the categories used in the "5A's Taxonomy for Determinants of Vaccine Uptake" [26].

\section{Access \\ Primary care accessibility and acceptability}

Providers considered access to primary healthcare to be a major barrier to vaccine uptake. In all 3 cities, providers reported that registration with general practice and lower primary care use were an issue amongst the communities. Lower usage of primary care by the communities was partly perceived as due to differences in health-seeking behaviours. Providers, particularly in Birmingham, noted that community members were more likely to access accident and emergency (A\&E) services than primary care, and only then once they felt very unwell.

'in their country they're not going to go to see the doctor, unless they're very ill and they're going to go straight to the hospital. You don't go through the GP.' (Provider 23)

Several providers felt that the concept of primary care and preventing illness was often not adopted by community members, with one provider reporting: 'they just don't believe in any medical intervention as such .... it's very low on their horizon and priority.' Other providers considered that uncertainties around entitlement to care

Table 1 Outbreak size and duration, and MMR vaccination coverage in Birmingham, Leeds and Liverpool (2017-18)

\begin{tabular}{lllll}
\hline & $\begin{array}{l}\text { Outbreak size (confirmed cases) } \\
\text { and duration }\end{array}$ & $\begin{array}{l}\text { MMR 1st dose at 24 months } \\
(2017-18)\end{array}$ & $\begin{array}{l}\text { MMR 1st dose at 5 years } \\
(2017-18)\end{array}$ & $\begin{array}{l}\text { MMR 1st and 2nd dose at 5 years } \\
(2017-18)\end{array}$ \\
\hline Birmingham & 116 cases (November 2017- June 2018) & $87.6 \%$ & $93.7 \%$ & $81.6 \%$ \\
Leeds & 36 cases (November 2017 to January 2018) & $92.9 \%$ & $95.8 \%$ & $88.2 \%$ \\
Liverpool & 22 cases (November 2017) & $93.0 \%$ & $95.0 \%$ & $86.2 \%$ \\
\hline
\end{tabular}


Table 2 5As Taxonomy for Determinants of Vaccine Uptake

\begin{tabular}{ll}
\hline Factor & Definition \\
\hline Access & $\begin{array}{l}\text { The ability of individuals to be reached by, or to } \\
\text { reach, recommended vaccines }\end{array}$ \\
Affordability & $\begin{array}{l}\text { The ability of individuals to afford vaccination, both } \\
\text { in terms of financial and non-financial costs (e.g. time) }\end{array}$ \\
Awareness & $\begin{array}{l}\text { The degree to which individuals have knowledge of } \\
\text { the need for, and availability of, recommended } \\
\text { vaccines and their objective benefits and risks }\end{array}$ \\
Acceptance & $\begin{array}{l}\text { The degree to which individuals accept, question or } \\
\text { refuse vaccination }\end{array}$ \\
Activation & $\begin{array}{l}\text { The degree to which individuals are nudged towards } \\
\text { vaccination uptake }\end{array}$ \\
\hline
\end{tabular}

prevented people from accessing health services until they became very unwell and realised that they could not self-manage their health.

In their engagement with the communities, providers found that navigating the health system was challenging and unclear for community members, particularly in the presence of language barriers. The process of registering with a general practice was not always clear. For instance, providers found that some community members were unaware of a need to register their new-born child at their GP practice, considering that this would be an automatic process if the mother was already registered there.

Experiences of discrimination were also not uncommon, specifically providers highlighted this in relation to encounters with GP receptionists.

'.to get to the GP you have to get past the front desk and it's the front desks that we are finding are really resistant to registering patients, following up, etc ... ...

Table 3 Providers

\begin{tabular}{llll}
\hline Organisation/job role & \multicolumn{3}{l}{ Number of interviews } \\
\cline { 2 - 4 } & Liverpool & Leeds & Birmingham \\
\hline $\begin{array}{l}\text { Public Health England - Health } \\
\text { protection team }\end{array}$ & 1 & 1 & 5 \\
$\begin{array}{l}\text { Screening and immunisation } \\
\text { team member }\end{array}$ & 1 & 2 & 1 \\
Practice nurse & - & 4 & 1 \\
General practitioner & - & 1 & \\
GP practice manager & - & 3 & 2 \\
Council & 1 & - & 4 \\
School nurse & 1 & - & - \\
Community immunisation nursing & 2 & - & - \\
team member & & & - \\
Social exclusion team member & 2 & - & - \\
Health visitor & - & - & 1 \\
Total = 33 & $\mathbf{8}$ & $\mathbf{1 1}$ & $\mathbf{1 4}$ \\
\hline
\end{tabular}

So first of all you've got to get passed the front desk, and if you don't speak English that's damn near impossible, and some of the receptionists are like out and out rude to the new arrivals, some of them are extremely hostile to registering patients, particularly if they are from Eastern Europe.' (Provider 8)

Amongst the CMs we spoke with, registration with a general practice had been reported as relatively easy; however, this appeared to be because the CMs had been helped in the process by friends and family. Amongst the CMs, their experiences of accessing general practice were largely positive, although they were aware of friends and family members that had experienced inadequate care.

'my mum lives here in the UK ... . but her general practitioner throws her out [of] the door every time she has problems because she can't speak English, they've got her out during the appointment. They've done this three times already. They push her out. And she's feeling really sick ... . she's afraid.' (Community member 6)

\section{Language and literacy}

CMs reported language and literacy as major barriers to accessing credible vaccine information and giving informed consent for vaccination. Providers also reported their awareness of these issues, and highlighted communication as a factor affecting their ability to properly explain vaccinations and to promote vaccination. The time-allotted to appointments with midwives and those working in general practice, reported as just $15 \mathrm{~min}$, was considered unrealistic, particularly when trying to overcome communication barriers.

Providers often struggled to distinguish the difference between Roma and Romanian, particularly when it came to language. Many Roma speak Romani as a first language, and the language of their nationality may be their second language. Romani has many different dialects and providers highlighted that access to a professional Romani speaking interpreter was not possible. Even when providers were aware that Romanian was not the preferred language for community members, or one they were proficient in, they remained reliant on accessing Romanian interpreters due to a lack of professional Romani interpreters. The use of Romanian interpreters could also be problematic, given the history between these groups

'... . some Roma communities feel very, apparently, badly treated by Romanians and therefore having a Romanian translator might not actually support understanding and translation. Well, [it] might 
Table 4 Community members

\begin{tabular}{|c|c|c|c|c|c|}
\hline No. & $\begin{array}{l}\text { Length of time } \\
\text { living in the UK }\end{array}$ & $\begin{array}{l}\text { Self-reported ethnicity } \\
\text { and nationality }\end{array}$ & Children & $\begin{array}{l}\text { Reported vaccination } \\
\text { status of children }\end{array}$ & Where vaccinated \\
\hline 1 & 3 months & Romanian & $\begin{array}{l}4 \text { children, age } \\
\text { range } 2-14 \text { years. }\end{array}$ & $\begin{array}{l}\text { Children fully } \\
\text { vaccinated. }\end{array}$ & Romania and the UK \\
\hline 2 & 3 years & Romanian & $\begin{array}{l}5 \text { children, age } \\
\text { range } 1.5-14 \text { years }\end{array}$ & $\begin{array}{l}\text { Children only } \\
\text { vaccinated with BCG. }\end{array}$ & Romania and the UK \\
\hline 3 & 1 year & Romanian & No children & N/A & $\begin{array}{l}\text { No recent vaccinations } \\
\text { (all vaccinations in childhood). } \\
\text { All vaccinations received in Romania }\end{array}$ \\
\hline 4 & 1 year & Romanian & $\begin{array}{l}5 \text { children, age } \\
\text { range } 5-16 \text { years }\end{array}$ & Children fully vaccinated & Romania and the UK \\
\hline 5 & 3 years & $\begin{array}{l}\text { Romanian - mother was } \\
\text { Romanian and father was } \\
\text { Roma Romanian }\end{array}$ & $\begin{array}{l}2 \text { children, aged } \\
7 \text { months and } 5 \text { years }\end{array}$ & Children fully vaccinated & Romania and the UK \\
\hline 6 & 2 years & Roma Romanian & $\begin{array}{l}4 \text { children, age } \\
\text { range } 1.5-13 \text { years }\end{array}$ & Children fully vaccinated & Romania and the UK \\
\hline 7 & 3 years & Romanian & $\begin{array}{l}3 \text { children, age } \\
\text { range } 6 \text { months- } 3 \text { years }\end{array}$ & Children fully vaccinated & Romania and the UK \\
\hline 8 & 2 years & Romanian & $\begin{array}{l}3 \text { children, age } \\
\text { range } 3 \text { to } 9 \text {. } \\
\text { Participant also pregnant } \\
\text { at the time of interview. }\end{array}$ & $\begin{array}{l}\text { Youngest child has not } \\
\text { been vaccinated. } \\
\text { Mother has also never } \\
\text { had any vaccinations. }\end{array}$ & $\begin{array}{l}\text { Romania and planned vaccinations } \\
\text { for her youngest child in the UK }\end{array}$ \\
\hline 9 & 5 years & Roma Romanian & $\begin{array}{l}2 \text { children, aged } 19 \text { and } 21 . \\
\text { One grandson aged } 4 \text { years. }\end{array}$ & $\begin{array}{l}2 \text { vaccinations declined } \\
\text { for grandson - flu and } \\
\text { another vaccination. }\end{array}$ & $\begin{array}{l}\text { Vaccinations for her children all } \\
\text { received in Romania. Vaccinations } \\
\text { for her grandson given in the UK. }\end{array}$ \\
\hline
\end{tabular}

introduce more problems and not solve the problem we're trying to solve.' (Provider 11)

Most of the CMs that we spoke with were able to access a Romanian speaking telephone interpreter at their GP practice. However, in their experience, providers were concerned that using telephone interpreters was not always effective.

'In your appointment, it's very hard to explain, with the language, what each illness is, and you sometimes wonder what the Language Line is actually saying, because you're trusting their interpretation. Sometimes the patient looks totally confused with the Language Line. So, it's a very hard job.' (Provider 14)

One CM also highlighted that those requiring an interpreter may not be aware that GPs are obligated to provide interpreting services. Instead they may seek their own interpreters, who may be potentially exploitative.

'there are a lot of dodgy people maybe on the internet who offer services, who offer to help you ... and they charge a lot.' (Community member 1)

CMs particularly reported a lack of interpreters available to explain school-based vaccinations, and in one instance an online translation tool was being using by health visitors. One $\mathrm{CM}$ had experienced difficulties in understanding and completing the informed consent form for her child's flu vaccination at school. Not being able to complete the form had meant that the child missed her flu vaccination at that time.

CMs also highlighted that literacy barriers may be an issue amongst the communities, and that written information (while useful) would not be accessible to everyone.

'it would be really helpful to have both - leaflets and some advice in person. With the leaflets is really hard because a lot of Romanians don't go to school and can't really read. So it's probably better or more helpful if they, somebody could explain to them in person, face to face.' (Community member 4)

In order to try and manage communication barriers, some CMs discussed having translation apps on their phones, or attending appointments with their family members.

'she will try to go [to the school] with her daughter, 11 years-old, because she's good at English, and maybe the daughter can help mum to understand everything about this immunization.' (Community member 6)

One CM also talked about receiving direct help from linking services at her local council to organise appointments. 


\section{Affordability \\ Perceived financial costs}

From their contact with community members, several providers reported a lack of clarity around payment for health services that could pose as a barrier to accessing healthcare and vaccination.

'... . if you are new into the country there are language issues, you don't know how to navigate the health system, how do you understand if you're one of those migrants that will be charged or won't be charged ... .' (Provider 1)

\section{Competing priorities}

In the context of other competing demands, vaccination was often not one of the main priorities for community members. The communities were described as having a more reactive response, living day-by-day, and dealing with immediate stressors. Competing priorities related to financial instabilities.

in the great scheme of things, vaccination tends to be a little bit lower down the list when you're struggle even to wonder what you're going to feed [your children], or how you're going to live for the rest of the day' (Provider 8)

Given this context, booking vaccination appointments in advance was not considered to be particularly effective, indicating the benefits of using a different approach such as drop-in vaccination sessions.

'The biggest problem we think exist is if you send them pre-booked appointments, so if you get them to book an appointment that just does not work; they don't live like that ... if you book them appointments, even if they've booked them themselves, it doesn't work, the DNA (did not attend) rates are very high. [They are more likely to come] if you tell them come this morning ... ...we've got a clinic coming like this morning, you can walk in. They understand that.' (Provider 12)

\section{Awareness}

Given the language and literacy barriers experienced by CMs, being able to locate credible information about vaccines in translated forms was difficult. The majority of CMs that we spoke with were not provided with written vaccination in translated forms. Several sought their information from family and friends, in addition to healthcare professionals. One CM also discussed the use of social media, accessing online chats and searching for information on YouTube.

Amongst the CMs that we spoke with, there was an awareness around the vaccine schedule in the UK; however, providers reported awareness as an issue within the communities.

'I think there was misunderstandings or wrong levels of awareness. I think people were saying to the school imms service when they were trying to offer MMR vaccinations or when the health protection team were asking parents about when their kids had their MMR, they were being told yes, they had the injection when they were born, and they are all okay. We are not quite sure what that was. I think we were all doubtful that it was MMR. It may just have been something else.' (Provider 11)

One provider in Birmingham had also heard the belief from community members that 'one shot cures all diseases', highlighting what appeared to be a lack of awareness around the vaccine schedule and the need for different vaccines for protection.

\section{Acceptance}

Perceptions around measles severity

Providers, particularly in Birmingham, reported that measles was not necessarily a disease that caused concern amongst the communities. Several providers believed that for some community members their children contracting measles was a 'rite of passage'

'the thought was that it wasn't particularly a disease that they [the Romanian communities] worried about, so I don't know whether it was the attitude to the vaccine or the attitude to the disease ... ..I know that they appeared not to be worried enough to have the vaccine.' (Provider 25)

It was considered beneficial to contract measles rather than vaccinate, so as to develop a 'natural immunity' to the disease.

In one family we had about eight members catch the virus, and they'll say, "Well, it's better to catch the natural infection than the injection." Well, that isn't always true, because you get a lot of symptoms, and we saw people in ITU and these were like young women, fit and healthy, and one ended up in ITU. She was really very ill, and could have died. We've had a couple of kids as well ... . I think they just think, "Measles, it's a bit of a rash and that's it," (Provider 15)

\section{Perceptions around the benefits of vaccination}

Amongst the interviewed $\mathrm{CMs}$, most considered vaccinations beneficial and important, particularly those 
that had witnessed vaccine-preventable diseases. CMs were often nervous ahead of their child's first vaccination, but this passed with positive vaccination experiences. A minority of CMs had not fully vaccinated their children as they believed that vaccines could cause more harm than good, producing damaging side effects.

I'm worried about illness and catching cold. Other children got sick afterwards, with swollen throats and then cancer and many other problems. Like lung diseases' (Community member 2)

'some children had one-week high temperature, some children because it was something with the nose, chocked and they couldn't breathe.' (Community member 9)

Amongst the CMs that declined vaccination, there was also the belief that vaccinations are ineffective. This was discussed particularly in relation to the influenza and MMR vaccine.

'other people had the vaccine against this disease, measles as you call it, they had the vaccine and still got the disease. This makes me doubtful ... ..I asked a nurse when I was in Romania. I asked her why do you have them vaccinations against measles if they don't protect children and they still get the measles? And she said it happens for them to still get.' (Community member 2)

Another belief was that vaccinations were unnecessary, as their children were well without.

'I didn't get the vaccines for my children neither in Romania nor here. None. I think it's the best way. They are much better this way. They don't catch cold, they don't get ill.' (Community member 2)

Other beliefs that providers had noted within the communities, which were not raised during interviews with CMs, were that vaccines could causes impotence, that vaccines are part of a conspiracy theory by religious leaders, and that vaccines contain human tissue.

\section{Trust in vaccinations and health services}

Past experiences of vaccinations and health care, in Romania and the UK, affected the decision to access vaccinations and health services amongst some of the community members. Understandably, negative experiences could create a distrust and fear of vaccines and health services. This highlights the importance of understanding the context of people's lives and how this shapes health decision-making.

II was afraid to have the vaccination for the boy. I was afraid because in Romania a lot has happened, I got scared and I refused ... . why did I refuse? Because someone in our village in Romania died because of the vaccination. The vaccine wasn't done properly. I was afraid when the boy was born to have the vaccine on him. I refused the vaccination ... .. the doctor no longer works there, he was put to trial. After the trial he was released from the hospital, they replaced him' (Community member 8)

Although it was unclear what exactly had happened to this child, the reporting of his death shortly after vaccination had generated a fear in the community. In this instance, the CM had become distrustful of doctors and subsequently concerned about vaccinations. This CM had also experienced other negative experiences of healthcare in Romania, in relation to herself and family members, which had formed her opinion that healthcare professionals are money-driven and cannot be trusted.

'In Romania, if you don't have money they leave you to die at home.' (Community member 8)

In the UK, this $\mathrm{CM}$ had gone on to experience positive experiences of healthcare, which in turn had changed her attitude towards vaccinations.

'after [I] saw how the NHS is here in England, [I] changed my mind ... . that's why I wanted the vaccination for my son, because the doctors are different here ....... .I] built up a relationship $n$ and confidence with professionals from NHS because [I was] in the hospital with the little one for a while one, when the little one was just 11 months old, and they saved his life' (Community member 8)

It was highlighted by providers that through discussion with community members trust could be developed and that this promoted vaccination uptake.

'... once I think I get a bit of a conversation going with the Roma mums, they do let me in and they will let me immunise. They're not against immunisations, they will let you immunise. That's the big difference I find, but it's that level of trust that you need to get with the Roma' (Provider 20)

\section{Activation}

Providers found that their blanket approach for reaching service users, such as GPs sending vaccination reminders 
to CMs via letter or text message, was not a particularly effective way of reaching the communities, particularly the Roma. This was due to communication barriers, and the transiency within Roma communities.

'... . this community really don't stay [anywhere] very long, so to even have an address is probably quite difficult ... . they seem to move on, and it's not the same people in houses from one week to the next.' (Provider 25)

Face-to-face communication was considered a much more effective approach to reaching communities and gaining their trust, using outreach strategies. In order to promote vaccination, although costly, providers also considered that it would be beneficial to involve members of the community as vaccine advocates. It was also felt that there needed to be a more integrated approach, involving different local organisations (e.g. schools, social care providers, local authorities, health visiting and midwifery services, and general practice) in identifying, understanding and building trust with communities.

\section{Discussion}

We found that contributing factors associated with ethnicity and nationality, including language and literacy, cultural and historical backgrounds, and experiences of discrimination and social exclusion, influenced vaccination uptake in the communities.

Factors related to access and acceptance, such as language and literacy barriers, navigating and registering with primary care, and trust in health services, were considered the main barriers to vaccination. Many of these barriers are also shared by other migrant and minority groups, across different countries [27-29]. The funding within the Romanian health system is concentrated in secondary care, and focused on treatment rather than prevention, which may help to explain the reported lower primary healthcare use amongst Romanian communities [30].

In our study we found that several community member participants that had declined vaccinations lacked trust in vaccines and health services, and that this was shaped by negative experiences of healthcare and discrimination in Romania and the UK. Discrimination and marginalisation have been highlighted elsewhere in the literature as barriers that appear particularly 'distinct' and heightened in Roma and Romanian communities [31-33]. Discrimination has been directed at Romanian communities in the UK who, as put by Fox, Moroşanu and Szilassy, 'have borne the brunt of public anxiety over Eastern European immigration' [34]. Romanians and Roma have been portrayed as communities to fear, and to hold in contempt $[34,35]$. The impact of Brexit has also contributed to this, with Roma particularly uncertain about their position in the UK [36].

Although concerns around vaccine safety and importance were reported these appeared to be less prominent factors affecting vaccination uptake. Uptake was therefore linked to the broader inequalities experienced by the communities [37].

The CMs that declined vaccination in this study demonstrated vaccine hesitancy, and their views were altered through gaining a trusting relationship with healthcare professionals. Trust can only be achieved through effective healthcare professional and provider engagement, which is reliant on the development and maintenance of links with communities. Developing trust largely relies on the development of mutual awareness and understanding between providers and community members, and the overcoming of communication barriers [33].

To promote vaccination uptake amongst the communities, new approaches must be adopted by providers that move away from traditional one-size-fits-all efforts. This will include a need to consider the use of outreach approaches and drop-in services. A shift towards mandating vaccination, which has been raised in the UK in relation to MMR, is unlikely to help in developing the trust needed for effective community engagement. We recommend that efforts are placed in engaging with communities, ensuring the availability of credible vaccine information and promoting the accessibility of health services and vaccinations.

\section{Strengths and limitations}

In conducting this research, we have reflected on the heterogeneity within Romanian and Roma communities, such as differences in linguistic skills and cultural backgrounds, and the importance of considering the influence of many variables affecting vaccination uptake. This is necessary to ensure that nationality and ethnicity are not simply used as a proxy for other variables [38].

In this study, we sought to identify and understand factors affecting vaccination uptake amongst Romanian and Roma Romanian communities in 3 areas affected by measles outbreaks in 2017-18. In speaking to providers, we gained insight into some of the main factors affecting uptake amongst those most at risk of vaccine-preventable disease.

The small number of CMs that we interviewed in this study were open, confident and mostly well-linked with health services and the community. Our participants were therefore not representative of less well-connected women in the communities; however, speaking with these women has provided valuable insight into some of the barriers to vaccination uptake faced by Romanian and Roma communities. We therefore anticipate that 
less connected women in the communities may experience greater barriers to vaccination and health services access.

In interviewing providers, it may have been that some of their comments were based more on stereotypes and preconceived ideas about the communities, rather than real life experiences. Providers acknowledged having few links and a lack of understanding of the communities.

\section{Conclusion}

We found that access and acceptance were dominant barriers to vaccination amongst the Roma and Romanian communities in this study, and that the development of trust from face to face contact between communities and providers is key to promoting vaccination. To establish and maintain trust providers must find ways to connect with and develop a greater understanding of the communities they serve. Better provider-service user relationships are essential to promote not only vaccination but also to reduce inequalities in health service access more broadly.

\section{Abbreviations}

CM: Community member; DNA: Did not attend; GP: General practice; GRT: Gypsy, Roma and Traveller; MMR: Measles, mumps and rubella; NHS: National Health Service; PHE: Public Health England; UK: United Kingdom; WHO: World Health Organisation

\section{Acknowledgements \\ We would like to thank the research participants for their time and contribution to this study. We would particularly like to thank the community members and group lead for inviting us to attend their wonderful community group.}

\section{Authors' contributions}

The study was designed by SB, VS and SMJ. SB was responsible for data collection and analysis. SB conducted the interviews. SB and SMJ were involved in data analysis. SB, MR and SMJ were involved in the interpretation of findings. SB produced the first draft of the manuscript. SB, VS, MR and SMJ contributed to revisions of the manuscript and gave final approval for the study to be published.

\section{Funding}

The research was funded by the National Institute for Health Research Health Protection Research Unit (NIHR HPRU) in Immunisation at the London School of Hygiene \& Tropical Medicine in partnership with Public Health England (PHE). The funders had no role in the design and conduct of the study; collection, management, analysis, and interpretation of the data; or preparation, review, and approval of the manuscript.

The views expressed are those of the author(s) and not necessarily those of the NHS, the NIHR, the Department of Health or Public Health England.

\section{Availability of data and materials}

All data relevant to the study are included in the article.

\section{Ethics approval and consent to participate}

The study received ethical approval and permissions from the London School of Hygiene and Tropical Medicine Observational Research Ethics Committee (Ref: 12124), the Health Research Authority (Project ID: 224734), and from Research and Development departments in the recruitment areas. The research was conducted in accordance with the 1964 Helsinki declaration and its later amendments or comparable ethical standards. Written informed consent was obtained from all study participants.
Consent for publication

N/A. No personal data included.

\section{Competing interests}

The authors declare that they have no competing interests.

\section{Author details}

1Department of Global Health and Development, Faculty of Public Health and Policy, London School of Hygiene \& Tropical Medicine, 15-17 Tavistock Place, London WC1H 9SH, UK. ²Department of Immunisation, Hepatitis and Blood Safety, Public Health England, London NW9 5EQ, UK.

Received: 20 November 2019 Accepted: 4 March 2020

Published online: 23 March 2020

\section{References}

1. Moss W. Measles. Lancet. 2017;390(10111):2490-502 [Online]. Available at: https://www.thelancet.com/journals/lancet/article/PIIS0140-6736(17)31463-0/ fulltext\#articlelnformation. [Accessed: 26/6/19].

2. World Health Organization (WHO) European Vaccine Action Plan 2015-2020 2014 [Online]. Available at: http://www.euro.who.int/_ data/assets/pdf_file/ 0007/255679/WHO_EVAP_UK_v30_WEBx.pdf?ua=1. [Accessed: 14/6/19].

3. WHO. Measles cases hit record high in the European Region. 2019a [Online] Available at: http://www.euro.who.int/en/media-centre/sections/pressreleases/2018/measles-cases-hit-record-high-in-the-european-region. [Accessed: 25.06.2019].

4. World Health Organisation (WHO). Measles - European Region. 2019b [Online]. Available at: https://www.who.int/csr/don/06-may-2019-measleseuro/en/. [Accessed: 14/6/19].

5. Public Health England. Measles cases in England: January to December 2018. 2019a [Online]. Available at: https://www.gov.uk/government/ publications/measles-mumps-and-rubella-laboratory-confirmed-cases-inengland-2018/measles-cases-in-england-january-to-december-2018. [Accessed: 08.08.2019].

6. Bell S, et al. I don't think anybody explained to me how it works': qualitative study exploring vaccination and primary health service access and uptake amongst Polish and Romanian communities in England. BMJ Open. 2019; 9(7):e028228.

7. Hargreaves $\mathrm{S}$, et al. Who is responsible for the vaccination of migrants in Europe? Lancet. 2018;391(10132):1752-4.

8. Public Health England. UK Measles and Rubella Elimination Strategy. 2019b. [Online]. Available at: https://assets.publishing.service.gov.uk/government/ uploads/system/uploads/attachment_data/file/769970/UK_measles_and rubella_elimination_strategy.pdf. [Accessed: 14/6/19].

9. Office for National Statistics. Population of the UK by country of birth and nationality: 2017. 2018 [Online]. Available at: https://www.ons.gov.uk/ peoplepopulationandcommunity/populationandmigration/international migration/datasets/populationoftheunitedkingdombycountryofbirthand nationalityunderlyingdatasheets. [Accessed: 26/6/19].

10. Brown P, Scullion L, Martin P. Migrant Roma in the United Kingdom: population size and experiences of local authorities and partners. Manchester: University of Salford; 2013.

11. Lane, Spencer, \& Jones. Gypsy, Traveller and Roma: Experts by experience. Reviewing UK Progress on the European Union Framework for National Roma Integration Strategies. Joseph Rowntree Foundation; 2014.

12. Brearley M. The persecution of Gypsies in Europe. Am Behav Sci. 2001;45(4): 588-99.

13. James Z. In: Hall N, Corb A, Giannasi P, Grieve J, editors. Hate Crimes against Gypsies, Travellers and Roma in Europe. London: Routledge: The Routledge international handbook on Hate crime; 2014. p. 237-48. 2014.

14. Burchardt $T$, et al. Experience of multiple disadvantage among Roma, gypsy and traveller children in England and Wales. London: Centre for Analysis of Social Exclusion, London School of Economics; 2018.

15. Equality and Human Rights Commission. England's most disadvantaged groups: Gypsies, Travellers and Roma - Is England Fairer? London: Equality and Human Rights Commission; 2016.

16. House of Commons Women and Equalities Committee. Tackling inequalities faced by Gypsy, Roma and Traveller communities: Seventh Report of Session 2017-19. 2019. [Online]. Available at: https://publications.parliament.uk/pa/cm2 01719/cmselect/cmwomeq/360/full-report.html. [Accessed: 25.05.2019]. 
17. Morris M. Roma communities \& Brexit - integrating \& empowering Roma in the UK. London: Institute for Public Policy Research; 2016

18. Tobi $\mathrm{P}$, et al. Health and social care needs assessment of eastern European (including Roma) individuals living in barking and Dagenham - final report. London: NHS Barking and Dagenham \& Institute for Health and Human Development, University of London; 2010.

19. Stan S. Transnational healthcare practices of Romanian migrants in Ireland: inequalities of access and the privatisation of healthcare services in Europe. Soc Sci Med. 2015;124:346-55.

20. Condon LJ, McClean S. Maintaining pre-school children's health and wellbeing in the UK: a qualitative study of the views of migrant parents. J Public Health. 2016;39(3):455-63.

21. Cook B, et al. Revisiting the evidence on health and health care disparities among the Roma: a systematic review 2003-2012. Int J Public Health. 2013; 58(6):885-911.

22. Duval $\mathrm{L}$, et al. The Roma vaccination gap: Evidence from twelve countries in Central and South-East Europe. Vaccine. 2016;34(46):5524-30.

23. Hajioff S, McKee M. The health of the Roma people: a review of the published literature. J Epidemiol Commu Health. 2000;54(11):864-9.

24. European Centre for Disease Prevention and Control. Surveillance report: Monthly measles and rubella monitoring report - April 2019. Period covered: 1 March 2018-28 February 2019. 2019. [Online]. Available at: https://www.ecdc.europa.eu/sites/portal/files/documents/monthly-measlesrubella-monitoring-report-april-2019.pdf/. [Accessed: 28.06.2019].

25. Braun V, Clarke V. Using thematic analysis in psychology. Qual Res Psychol. 2006;3(2):77-101.

26. Thomson A, et al. The 5As: A practical taxonomy for the determinants of vaccine uptake. Vaccine. 2016;34(8):1018-24 [Online]. Available at: https:// www.sciencedirect.com/science/article/pii/S0264410X15017466?via\%3Dihub. [Accessed: 18.06.2019].

27. Aung NC, Rechel B, Odermatt P. Access to and utilisation of GP services among Burmese migrants in London: a cross-sectional descriptive study BMC Health Serv Res. 2010;10:285.

28. Gerrish $\mathrm{G}$, et al. Bridging the language barrier: the use of interpreters in primary care nursing. Health Soc Care Comm. 2004:12(5):407-13.

29. Scheppers $\mathrm{E}$, et al. Potential barriers to the use of health services among ethnic minorities: a review. Fam Pract. 2006:23(3):325-48.

30. Organisation for Economic Co-operation and Development. State of Health in the EU Romania: Country Health Profile 2019. European Observatory on Health Systems and Policies. [Online]. Available at: https://ec.europa.eu/ health/state/country_profiles_en. [Accessed: 24.01.2020].

31. Craciun C, Baban A. "Who will take the blame?": Understanding the reasons why Romanian mothers decline HPV vaccination for their daughters. Vaccine. 2012;30(48):6789-93.

32. McFadden A., et al. Enhancing Gypsy, Roma and Traveller peoples' trust: using maternity and early years' health services and dental health services as exemplars of mainstream service provision. Final Report September 2018. 2018. [Online]. Available at: http://qna.files.parliament.uk/qna-attachments/1 038929/original/Report_on_GRT_health.pdf. [Accessed: 16.07.2019].

33. Rechel B, et al. Access to health care for Roma children in central and Eastern Europe: findings from a qualitative study in Bulgaria. Int J Equity Health. 2009:8:24.

34. Fox JE, Moroşanu L, Szilassy E. Denying Discrimination: Status, 'Race', and the Whitening of Britain's New Europeans. J Ethn Migr Stud. 2015;41(5):729-48.

35. Light $\mathrm{D}$, Young $\mathrm{C}$. European Union enlargement, post-accession migration and imaginative geographies of the 'New Europe': media discourses in Romania and the United Kingdom. J Cult Geogr. 2009;26(3):281-303.

36. Tileaga C. \& Popoviciu S. Where next for migrant Roma communities postBrexit? [Online]. openDemocracy. 2018. Available at: https://www. opendemocracy.net/uk/cristian-tileag-salomea-popoviciu/where-next-formigrant-roma-communities-post-brexit. [Accessed: 01/07/2019].

37. Newton P., and Smith DM. Factors influencing uptake of measles, mumps and rubella (MMR) immunization in site-dwelling Gypsy, Roma and Traveller (G\&T) communities: a qualitative study of G\&T parents' beliefs and experiences. Child: care, health and development. 2017. 43; 4: 504-510.

38. Ellison GTH. 'Population profiling' and public health risk: when and how should we use race/ethnicity? Crit Public Health. 2005;15(1):65-74.

\section{Publisher's Note}

Springer Nature remains neutral with regard to jurisdictional claims in published maps and institutional affiliations.

Ready to submit your research? Choose BMC and benefit from:

- fast, convenient online submission

- thorough peer review by experienced researchers in your field

- rapid publication on acceptance

- support for research data, including large and complex data types

- gold Open Access which fosters wider collaboration and increased citations

- maximum visibility for your research: over $100 \mathrm{M}$ website views per year

At BMC, research is always in progress.

Learn more biomedcentral.com/submissions 